\title{
De la filosofía analítica al teísmo: Antony Flew
}

\author{
(From Analytic Philosophy to Theism: \\ Antony Flew)
}

\author{
ENRIQUE R. MOROS \\ Facultad Eclesiástica de Filosofía \\ Universidad de Navarra \\ enmoros@unav.es
}

Resumen: Después de los grandes sistemas idealistas, del advenimiento del nihilismo y de la formulación del pragmatismo, la filosofía recomienza de nuevo de modo creativo. Para comprender este surgimiento, argumentaré acerca de la imprescindible relación que la filosofía debe tener con la ciencia. A continuación, delinearé, al hilo de la historia de Antony Flew, los principales argumentos filosóficos ateos presentes en la filosofía analítica, y las características peculiares que adoptan los viejos argumentos. Y, finalmente, intentaré formular con la mayor precisión posible los principales argumentos para demostrar la existencia de Dios que se están discutiendo ahora mismo en el seno de la tradición analítica.

Palabras clave: filosofía analítica; Dios; ateísmo; Antony Flew.

\begin{abstract}
After the great idealistic systems, the advent of nihilism and the formulation of pragmatism, philosophy restarts again creatively. To understand this rise, I will argue about the essential relationship that philosophy should have with science. Then I will delineate, in line with Antony Flew's history, the main philosophical arguments atheists present in analytic philosophy, and the characteristics that take the old arguments. Finally, I will try to formulate as accurately as possible the main arguments for the existence of God being discussed right now within the analytic tradition.
\end{abstract}

Keywords: Analytic Philosophy; God; Atheism; Antony Flew. 
A la filosofía le corresponde un lugar discutido, siempre por determinar. A la propia filosofía le atañe continuamente definir su propio territorio, el lugar y el alcance de su propio saber y su relación con los demás conocimientos y con la cultura que vivimos. Ya Platón otorgaba un lugar intermedio a la filosofía: ni participaba en la Juegos Olímpicos ni hacía su agosto a propósito de los mismos (Kirk and Raven 2008, 322). En cambio, admiraba las habilidades de todos, disfrutaba viendo las maravillas de las que eran capaces los atletas y se asombraba del poder de la libertad que une a los hombres en equipo. Es amor al saber, no su acabada posesión; por eso Aristóteles llama a la metafísica ciencia buscada: porque el amor es hábil en buscar y propiciar encuentros que nos permitan relacionarnos con la verdad y servirla de la mejor manera que podamos. Estas páginas han nacido al hilo de la lectura de un libro muy singular, porque implica un camino y, a la vez, señala un testimonio (Flew 2012). Intentaré, pues, mostrar los rasgos característicos de ese testimonio y destacaré los hitos más sobresalientes del desarrollo de la filosofía analítica en torno al teísmo, es decir, lo que se ha pensado sobre la existencia de Dios en las últimas décadas.

Así, después de unas consideraciones sobre la situación histórica del origen de la filosofía analítica delinearé la relación que la filosofía debe tener con la ciencia. A continuación, mostraré al hilo de la historia de Antony Flew los argumentos filosóficos ateos presentes en la filosofía analítica. Y finalmente, intentaré formular con la mayor precisión posible los principales argumentos para demostrar la existencia de Dios que se están discutiendo ahora mismo en el seno de la tradición analítica.

La posición de la filosofía en el siglo XX ha sido verdaderamente singular. Si en el siglo XIX tuvo lugar la apoteosis de la filosofía alemana, fue también, sin duda, el momento en que se firmó el acta de su defunción. Con la muerte de Nietzsche acaba también el siglo y florece el nihilismo: el Siglo XX es como el siglo de la nada. Incluso ha sido denominado 'el siglo breve' ${ }^{1}$ : casi la nada temporal. No es ajeno a este curso de la historia el

1 Parece que fue el historiador inglés Eric Hobsbawm quien llamó así al siglo XX al considerar que propiamente comienza con la I Guerra mundial y termina con la caída de los regímenes comunistas del Este de Europa (Hobsbawm 1995). 
asombroso éxito de la ciencia. Durante los diez años que dura la locura de Nietzsche tiene lugar el desarrollo más impresionante de la ciencia física desde Newton. Podría decirse que la filosofía continental es en buena medida la heredera de aquella ausencia de la realidad, mientras que la filosofía analítica mira sobre todo el desarrollo del conocimiento científico.

La filosofía en el siglo XX, suele decirse, ha perdido así su condición de saber sobre la realidad en beneficio de la ciencia con el resultado del desencantamiento del mundo, según el diagnóstico de Max Weber ${ }^{2}$. A este diagnóstico cabe oponerle dos objeciones. En primer lugar, sólo el neopositivismo lógico ha aceptado esa situación para la filosofía según la cual la filosofía es sólo metodología y análisis del lenguaje unificado de las ciencias. El neopositivismo lógico nace justamente en Austria y se extiende en Inglaterra gracias a Ayer y en EE.UU. gracias en parte a la emigración propiciada por el éxito de Hitler. Pero aceptar esa posición conlleva inevitablemente aceptar la división radical entre ciencia y humanidades y dar por buena la división entre las dos culturas, instalarse en la esquizofrenia personal y social ${ }^{3}$.

La filosofía analítica, sin embargo, recorre otros caminos: el desarrollo de la lógica, la atención al lenguaje ordinario, el cuidado del rigor argumentativo y la claridad expositiva, el diálogo constante con la investigación científica... Desde esta perspectiva la filosofía analítica comparte muchas

2 El concepto aparece en su obra La ciencia como profesión (Weber 2009). El libro se publicó en 1919 y el texto más significativo dice así: "La intelectualización y racionalización crecientes no significan, pues, un creciente conocimiento general de las condiciones generales de nuestra vida. Su significado es muy distinto; significan que se sabe o se cree que en cualquier momento en que se quiera se puede llegar a saber que, por tanto, no existen en torno a nuestra vida poderes ocultos o imprevisibles, sino que, por el contrario, todo puede ser dominado mediante el cálculo y la previsión. Pero esto significa el desencantamiento del mundo. A la inversa del salvaje, el cual aún cree que tales poderes existen, nosotros no tenemos que valernos de medios que obren efectos mágicos para controlar a los espíritus. O incitarlos a la piedad. Esto es algo que se puede lograr por medio de la técnica y la previsión. He ahí, en esencia, el significado de la intelectualización”.

3 Más allá del éxito o del fracaso intelectual del neopositivismo, la idea de las dos culturas ha cuajado en la sociología del conocimiento y en las preocupaciones intelectuales de los filósofos. El punto de partida fue el libro The Two Cultures (Snow 1959). Sólo en castellano podemos referirnos a escritos que tienen este tema como eje a Carlos Castrodeza (Castrodeza 2000), Antonio Diéguez Lucena (Diéguez Lucena 2000) y Julián Pacho (2011). 
de las características metodológicas del aristotelismo: su arraigo pedagógico, el valor de la experiencia sensible, el gusto por el rigor, la audacia para inquirir... incluso la búsqueda de la causa final del universo. Una filosofía que no sea conocimiento de la realidad no es conocimiento de nada y así ya puede darse por terminada. Casi todos los que han firmado la defunción de la filosofía han sido enterrados antes que ella, que a pesar de todo goza de excelente salud, puesto que hoy, aquí y en todas partes, provoca vivas discusiones que no parece que vayan a tener fin... si no fuera ningún conocimiento de nada seguro que a nadie la importara verdaderamente nada, entonces ¿por qué alguien se molestaría en discutir algo que no tiene ningún interés?

La propuesta de que las ciencias empíricas incluyen y completan el conocimiento del mundo hoy recibe el nombre de naturalismo. Pero el naturalismo, como el principio de verificación neopositivista, se autorrefuta: su propia afirmación no puede hacerse naturalmente, sino que requiere del ejercicio de la razón universal que ninguna ciencia empírica ejerce propiamente. No hay, en realidad, ningún científico naturalista, sólo filósofos que naturalmente pueden estar completamente tan equivocados como el que escribe estas líneas. Por esa misma razón, la filosofía no puede ser una ciencia natural, porque la razón no es un asunto natural, aunque sea perfectamente natural para los hombres tener la facultad de la razón. Pero su ejercicio es un compromiso y una responsabilidad: forma parte de la vida ética de la persona. Y es que en el ser humano la naturaleza se trasciende a sí misma y apunta, más allá de sus propios límites, a su origen y a su fin, manifiesta su orden maravilloso y hace resplandecer la verdad y el bien que le pertenecen como regalos preciosos (Moros 2008).

Y, de este modo, llegamos a la segunda objeción que quisiera exponer a la observación de Weber que se resumía en la palabra "desencantamiento". Puede parecer, en efecto, que el resultado del saber científico es realmente el desencantamiento del mundo: allí donde antes vivían las ninfas, en los campos poblados de gracias, en las estrellas que manifestaban los destinos de dioses y hombres, en los vuelos de las aves que permitían la lectura de la buena suerte en las batallas... ahora no hay nada sino frías 
ecuaciones y fuerzas ciegas que ejercen un poder oscuro e inmisericorde sobre las cosas. Pero eso, en realidad, ya lo había hecho antes y mejor el cristianismo: no hay más Dios que el único Dios, el Padre de nuestro Señor Jesucristo, que ha puesto el mundo a nuestro servicio, para que lo dominemos y construyamos la ciudad de los hijos de Dios donde reine el amor. No, la ciencia no desencantó el mundo ya desencantado, sino que el mundo desencantado por el cristianismo permitió que el universo entero fuera objeto de la investigación científica y motivó la injerencia técnica de los hombres en el discurrir de las cosas (Artigas 2004). El mito de la edad de oro en el que la tierra todavía no había sido herida por el hierro del arado es totalmente pagano. Dios hizo el mundo para que sirviera al hombre.

El descubrimiento de los montes de la luna no significa sólo que la luna sea como la tierra sino que la obra que Dios ha puesto a nuestro alcance es más grande de lo que pensábamos. El descubrimiento de los satélites mediceos de Júpiter vuelve a ampliar la obra divina. Y el espectáculo del sistema solar con las maravillosas órbitas elípticas calculadas por Kepler sólo puede ser un canto a la sabiduría divina que ordena las cosas con suavidad y justicia. Pero si damos un salto a los descubrimientos astronómicos y cosmológicos de las últimas décadas o a las profundidades del átomo que la mecánica cuántica nos ha permitido acceder, incluso hasta la partícula de Dios o bosón de Higgs recién descubierto, pensar en el desencantamiento de la realidad que produce la ciencia deja de tener por completo sentido alguno: las maravillas de lo más grande y de lo más pequeño no dejan de admirarnos en la investigación científica más avanzada, a nosotros, que somos aficionados, y a los científicos más avezados.

Basten estos párrafos como comentario sobre la desafortunada expresión que tanta fortuna hizo a lo largo del S. XX. Pero, ¿Por qué tuvo tanto éxito una fórmula tan equivocada? La cuestión no es fácil, porque el S. XX es muy complicado: ¿cómo no va a serlo, si en el plazo de 25 años el mundo se mató entre sí dos veces casi por completo y otras muchas veces en parte, y los hombres cometieron las mayores tropelías que recuerda la historia una vez tras otra, en un país tras otro, cuando la información se hizo universal y las noticias llegaban a todas partes y los medios técnicos para hacer 
el mal permitían hacerlo en proporciones hasta entonces desconocidas? ¿Por qué después de Auschwitz, el Gulag, y después del Gulag, la revolución cultural, y después de la revolución cultural Pol Pot? ¿No habrá, acaso, un hilo rojo que una el deseo del desencantamiento del mundo con la angustia de la libertad analizada por el existencialismo ateo y la desesperación en la que ha desembocado la revolución sexual de mayo del 68? Quizá una idea equivocada de libertad presida todas estas manifestaciones y la paralización de la cultura y la crisis económica en la que nos encontramos.

La filosofía no puede renunciar a ser conocimiento auténtico de la realidad y, por esa razón, no puede dejar de cultivar la relación constante con la ciencia, con la investigación científica. La metafísica se llama así, desde el principio, por venir después de la física. Sin física no es posible la metafísica. Aristóteles al hacer la primera historia de la filosofía en los libros de la metafísica comienza llamando a los primeros filósofos físicos, porque investigaban la naturaleza e inquirían por la causa material. Sin esa exploración nunca hubiera aparecido la metafísica. Pertenece también al genio de Aristóteles la creación y el desarrollo de la biología en muchas de sus especialidades, es decir, de las ciencias de la vida. Probablemente si San Alberto no hubiera sido tan grande, Santo Tomás hubiera tenido que dedicar mucho más tiempo a la investigación empírica. Una filosofía que no esté suficientemente atenta a la ciencia probablemente acabará siendo una filosofía que no se ocupa de la realidad y termina por no tener nada real que decir. Así resulta lógico que no sea escuchada.

Lo contrario de una filosofía atenta a la investigación científica es una filosofía centrada en la interpretación, entendida exclusivamente como hermenéutica de la vida cultural humana, que es sólo historia de las ideas. Suele decirse que la diferencia entre la filosofía continental y la filosofía analítica en realidad es sólo que una se escribe en inglés y la primera en cualquier otro idioma. Obviamente esto es una broma contra la reticencia americana a aprender idiomas, especialmente alemán. Pero oculta una realidad de fondo: en Europa sabemos demasiadas lenguas pero hemos perdido de vista las cosas mismas. El grito de Husserl con el que dio comienzo a la fenomenología no parece haberse tomado realmente en serio. 
Es verdad que la filosofía analítica se escribe en inglés, pero también es verdad que lo que les interesa es la realidad, mientras que a los continentales, si se nos permite agrupar a personas y sensibilidades tan diversas en un solo nombre, estamos muchas veces tan interesados en la corrección, en la oportunidad de lo que decimos, en la certeza de lo que afirmamos, en los temas culturales que tratamos, que hemos abandonado a los técnicos todo interés por la investigación científica. Y de ese modo traicionamos a la filosofía misma. Sólo en EEUU parece posible escribir un libro sobre On bullshit (Frankfurt 2006), mientras que en Europa parece que demasiada gente escucha con gusto a charlatanes y sacamuelas.

Esa conexión con la ciencia y el contexto universitario de la filosofía americana definen en buena medida los perfiles de la filosofía analítica. Esos perfiles determinan un contexto humano de búsqueda que supera el cientificismo y el racionalismo. Pero también perfilan una entraña humana de temas y modos de hacer que rechazan la imposición ideológica de lo políticamente correcto. Permiten el diálogo y definen las normas del enfrentamiento intelectual. Por eso un ateo tan famoso como Dawkins cuyos libros se venden por millares ni se citan sino para reírse en un contexto universitario: él vive de un millonario que paga su cátedra, es un auténtico sofista, que ha sobrevivido 25 siglos a la Atenas de Gorgias, pero cuya cultura filosófica no alcanza ni el nivel mínimo para aprobar el bachiller, ni su actitud intelectual merece no ya la cita sino ni siquiera la crítica.

"El fallo de Dawkins como académico ha sido su negativa escandalosa y aparentemente deliberada a presentar en su forma más fuerte la doctrina que él parece pensar que ha refutado... Sin embargo, un académico que ataca una posición ideológica que él cree que debe estar equivocada tiene, por supuesto, que atacar esta posición en su forma más fuerte. Eso no lo hace Dawkins... y su fallo es el indicador decisivo de su falta de un sincero propósito académico y, por tanto, me da título para acusarlo de haberse convertido en algo que él probablemente consideraría imposible: un fanático laicista” (Flew 2012, 11). Este es el contexto de la filosofía analítica. Aquí son posibles todas las posiciones intelectuales en relación a la existencia de Dios, siempre que se expliciten con claridad y se defiendan con rigor. 
Por eso, la filosofía sabe que no existe ella sola en el saber humano, y ni siquiera es el primer saber que posee el hombre: los seres humanos llegan a la filosofía ya llenos de ideas. La idea de Dios, en concreto, no es una invención de la filosofía. Uno comienza a filosofar ya desde la aceptación de Dios, como Plantinga o Swinburne, o desde su rechazo como Flew.

En una sociedad cristiana, en la que Dios está presente al menos nominalmente, los hombres, al llegar a la edad de la razón, cuando comenzamos a pensar, no nos queda otra que plantearnos el tema de Dios. Pero esto ocurre también en otras culturas e incluso en todas. La filosofía, por ejemplo, al decir de Aristóteles, comienza con Tales, para quien el agua tiene caracteres divinos, pero es algo material: una maravillosa combinación de teísmo y materialismo en el s. VII antes de Cristo. Alguien ha dicho que pensar en, en definitiva, pensar a Dios. Descubrirse pensando el mundo equivale a descubrir la diferencia entre la razón y el mundo y buscar el origen de esa diferencia es inquirir directamente por Dios. Eliminar a Dios del horizonte intelectual de una persona viene a ser como amputar uno de sus miembros más importantes: quizá consiga vivir muy limitadamente sin él, pero nunca vivirá a gusto. Quizá ni siquiera a eso se le pueda llamar vivir en ningún sentido digno del hombre. Pero, en definitiva, resulta mucho más fácil amputar un miembro del cuerpo que eliminar a Dios del horizonte de los hombres. En realidad es estrictamente imposible salvo que fuéramos capaces de eliminar la propia razón. Porque el cultivo de la razón, que es tanto el desarrollo de la ciencia, como la práctica de las humanidades y el ejercicio de la filosofía, tiene su propio dinamismo, un desarrollo que el propio Kant considera inevitable e inesquivable. Si hay razón, Dios comparece siempre.

Hace ya tiempo Ratzinger distinguía dos tipos de ateísmo: uno reactivo y otro positivo (Ratzinger 1973). El reactivo se incluye en la propia dinámica religiosa de la humanidad y resulta necesario para compensar la tendencia antropocéntrica de los hombres para dibujar a los dioses a su propia medida. El positivo, en cambio, tiene su origen en la pretensión humana de ser como dios. Pero esa pretensión no puede, por mucho que lo intente, dejar de ser también reactiva: según sea el dios al que pretendas sustituir, 
así será el dios que pretendes ser. Por eso el único ateísmo interesante es el que pretende enfrentarse al único Dios verdadero, es decir, sólo después del monoteísmo cristiano es posible encontrar un Dios interesante como para que su negación pueda merecer alguna atención intelectual de relieve. Sólo después del esfuerzo teológico de los cristianos, sostenido durante siglos, para entender lo que creemos, puede tener algún valor la negación de ese Dios tantas veces pensado, reflexionado con tanta atención y examinado con todos los instrumentos que la sabiduría humana ha encontrado para evaluar la coherencia y consistencia de lo conocido.

La máxima filosófica según la cual "primum vivere, deinde philosophare”, que tantas veces resulta grata e incluso divertida, se aplica también a la cuestión de Dios. Uno no llega a la filosofía como una tabla rasa y la filosofía no es nunca su primer pensamiento. La filosofía es tarea de madurez, como ya vio Platón. Y supone siempre rectificación de las ideas falsas que uno se ha formado, corrección de los puntos de vista inadecuados que ha estado manejando, soltura para librarse de ataduras que aprisionan la libertad para descubrir la verdad y el bien. Por eso Sócrates sigue siendo el modelo del filósofo, porque su inquisición sigue golpeando nuestra tranquila mala conciencia, porque su ejemplo no nos deja cómodos con las doctrinas ya elaboradas en vez de seguir buscando, porque su muerte no nos puede dejar indiferentes ante el desarrollo de la cultura de muerte que nos rodea.

Por eso C.S. Lewis, el gran apologista cristiano, fundó en Oxford el círculo socrático, para recordar a todos que debemos seguir la argumentación hasta dondequiera que nos lleve (Flew 2012, 48). O seguir la evidencia adondequiera que lleve (Flew 2012, 59). Este es el hilo conductor del itinerario que narra Anthony Flew en primera persona y que tiene todo el sabor de una clásica confesión. Pasamos así a la segunda parte de este artículo.

De este motto, por usar una metáfora musical, me parece que se deben destacar tres cosas: primero, que hay un argumento, es decir, no una simple idea, una mera inspiración, sino una secuencia coherente y rigurosa de proposiciones articuladas siguiendo las reglas de la lógica y que reclaman para sí la verdad. En segundo lugar, que ese argumento desarrollado lógicamente exige un corazón que lo desarrolle personalmente: no hay máquina 
filosófica que valga, se precisa un corazón humano que haga valer la verdad del mismo. Por último, que el hombre que desarrolla ese argumento tiene que sentirse concernido en su mismo ser por aquello mismo que está pensando, es decir, que pensando se está jugando la vida: así en la filosofía se decide el valor de la vida, y en la vida se muestra todo el valor de la filosofía. Sin pensar, la vida humana no valdría nada. Entiéndase, renunciando a pensar, la vida del hombre deja de ser humana en la misma medida en que es una renuncia voluntaria. La filosofía es el puente que une el producir una prueba y el persuadir a una persona, porque la persona que se deja persuadir es la que puede ver el valor de la prueba y así amar la verdad que se desvela en ella. La autobiografía de Flew es la historia de cómo la pasión por la verdad, el gusto por los argumentos bien fundados y cuidadosamente desarrollados alcanzan a tocar el mismo centro del alma humana.

Anthony Flew es hijo de un pastor metodista y desde su adolescencia decidió ser ateo. La primera razón que alumbró tenía que ver con el problema del mal: "la idea de un Dios que es al mismo tiempo omnipotente e infinitamente bueno es incompatible con los males e imperfecciones manifiestos en el mundo" (Flew 2012, 44). A continuación rechaza que "el universo hubiese sido creado por un Dios supremamente bueno y todopoderoso" (Flew 2012, 45). Este es el bagaje con el que llega a la universidad, a la filosofía, junto con un excesivo interés por las cuestiones parapsicológicas, según dice él mismo (Flew 2012, 48).

En Oxford tiene como maestro a Gilbert Ryle, que tampoco es creyente, pero le enseña y le hace gustar la filosofía. Y, en el Socratic Club lee su primer trabajo, “Teología y falsificación”. Una vez reelaborado aparece como artículo en una obra que hará escuela y que puede considerarse un hito en la historia del ateísmo contemporáneo. Se trata de una obra colectiva que editaron en 1955 Flew y Alasdair MacIntyre y que llevaba el título de New Essays in Philosophical Theology (Flew and MacIntyre 1972). Esta obra se convirtió en todo un desafío para los creyentes desde la perspectiva de la nueva filosofía que se estaba desarrollado en Inglaterra, lo que se llamaría después filosofía analítica. En realidad el desafío estaba vivo en los ambientes intelectuales, pero esta obra lo puso blanco sobre negro, con el 
vigor y la audacia del que sabe que está abriendo un camino nuevo en la historia del pensamiento.

Los intelectuales ingleses desde el siglo anterior en su mayoría habían dejado de ser creyentes, pero en términos generales todavía no sabían que eran ateos y los cristianos no se sentían urgidos a elaborar verdaderos argumentos que pudieran convencerles. En 1948 tuvo lugar el famoso debate radiofónico entre Russell y Copleston ${ }^{4}$. Cuando uno lo oye o lee las transcripciones no deja de asombrarse del pánico de Russell ante la poderosa argumentación de Copleston: no hay quien le saque del no: no hay suficiente evidencia, no podemos conocer lo que está tan alejado de nuestra experiencia, no sé qué significa contingente aplicado a las cosas mismas en vez de a las proposiciones, no sé qué es la obligación moral... Cuando uno lee las evaluaciones de aquel debate se sorprende de que inmediatamente parecía que ganaba Russell y a medida que ha pasado el tiempo las posturas se inclinan a favor de Copleston. Quizá porque éramos adolescentes y nos gustaba oponernos a la visión heredada. Quizá porque hemos ido descubriendo que por muchos «nos» que juntemos no sale ningún sí, y sin afirmaciones el saber se encuentra vacío y sin un saber sólido y sabroso no se puede educar, no hay nada que enseñar. Se puede ser agnóstico o ateo como reacción, pero cuando esa postura se convierte en moneda de uso, entonces uno ya no es nada: solo cabe el silencio... el silencio sobre Dios que amenaza con prolongarse inmediatamente con el silencio sobre el hombre y que la conversación común gire exclusivamente en torno a los intereses y a su defensa, es decir, a la ley de la selva.

Por eso, de repente estalla la crisis: la publicación de este libro pone de manifiesto la situación real de los intelectuales ingleses a mediados del S. XX. La situación es magistralmente descrita por el título de otro libro famoso: El milagro del teísmo (Mackie 1994). Es un verdadero milagro que todavía haya personas inteligentes que crean en Dios, aunque como mostró Hume los milagros no existen y si existieran no podríamos saber que son tales. No sé si este libro se tradujo relativamente pronto al castellano

4 Se puede consultar la versión escrita en (Russell and Copleston 1978). Puede verse en YouTube subtitulado en castellano en http://www.youtube.com/watch?v=bb1y0hYhEEQ. 
porque el autor era muy conocido o porque el argumento era excelente o porque era una declaración de ateísmo. Pero me inclino por la tercera posibilidad.

Volvamos a Flew y su primera obra. En realidad, su objetivo era muy limitado y que él denomina el argumento de las mil calificaciones: "estaba desafiando a los creyentes religiosos a que explicaran cómo deben ser entendidas sus afirmaciones, especialmente a luz de los datos que chocan con ellas" (Flew 2012, 61). Si hay que añadir tantas cosas para que se entienda que Dios es amor que al final no se entiende nada, en realidad no hemos dicho nada. En terminología clásica, se diría que estaba pidiendo al creyente que mostrara la consistencia de la existencia de un Dios como el que la religión sostiene que adora con las características de este mundo en el que vivimos. En realidad, nada más puesto en razón que esta petición. Si los creyentes no podemos hacer esta tarea, en realidad hemos renunciado completamente a la racionalidad de nuestra fe. Pero desde los primeros cristianos, la fe no sólo se ha tenido como racional sino como verdadera. Así, reconoce Flew que su escrito ayudó a "remover la calma chica del discurso teológico” (Flew 2012, 62). Es claro, por otro lado, que estas objeciones no son de gran calado y fueron correctamente respondidas, como él mismo reconoce, en al menos dos casos: Basil Mitchel sostuvo que, precisamente porque Dios es amor y existe el mal, surge la cuestión de la teodicea, es decir los cristianos somos intelectualmente serios, aunque no siempre tengamos a mano respuestas al gusto de los objetores; por otro lado, Raeburne Heimbeck se encargó de mostrar un error lógico en la argumentación de Flew: no es lo mismo "contar en contra de" que "ser incompatible con”: el argumento sólo funciona respecto de lo segundo, pero no respecto de lo primero.

Once años después publica Dios y la filosofía (Flew 1976a), toda una argumentación sistemática a favor del ateísmo "tan poderosa como pude" (Flew 2012, 63). De este declaración merece destacarse en primer lugar que según Flew en 1966 no había ningún tratado de teología natural al alcance de un reputado profesor de filosofía de habla inglesa que a su vez tuviese la aquiescencia de los filósofos creyentes a quienes consultó. Considero que 
esta afirmación no es del todo justa, pero es cierto que nunca se hallarán suficientes libros buenos para cualquiera que los busque. La cuestión clave que plantea Flew en su libro es la coherencia de los atributos divinos y su aplicabilidad. Es decir, ¿cómo puede reconocerse a Dios? Este modo de plantear la cuestión era ciertamente original, pero en realidad no era justo, como se encargaron de mostrar Richard Swinburne, en The Coherence of

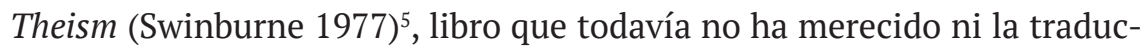
ción al castellano -aunque en los dos últimos años se han traducido otras dos obras de este autor-, y Frederick Copleston.

La tercera obra de Flew en su camino en el ateísmo filosófico militante se titula La presunción del ateísmo (Flew 1976b). El tema clave que sale a la luz en esas páginas es a quién le corresponde la carga de la prueba en la cuestión de la existencia de Dios: quién debe actuar de fiscal y quién debe limitarse a desempeñar el rol del abogado defensor. A cualquiera de ustedes no se le escapa que se trata del tema decisivo en la teoría de la argumentación: quién debe dar las pruebas positivas y quién tiene el beneficio de la duda. La idea de fondo es que para creer en Dios necesitamos buenas razones. En este punto, Flew inventa una nueva posición teórica: el ateísmo negativo, según el cual no se puede demostrar la existencia de Dios y por tanto el ateísmo goza de la presunción del favor de la verdad. Pero las respuestas fueron inmediatas. Anthony Kenny mostró que la posición que goza del favor de la prueba no es ni el teísta ni el ateo, sino el agnóstico; porque saber requiere más esfuerzo que no saber; pero el agnóstico, aunque no sepa, no por eso le vale para aprobar el examen: puede tener obligaciones para saber algunas cosas. Kay Nielsen, también ateo, sostuvo que para que la argumentación fuera buena debería mostrarse que hay un concepto común de racionalidad, pero sin él lo que hay es una gran interrogante delante de la presunción de ateísmo (o del teísmo). La respuesta más radical la dio Alvin Plantinga con la idea de que la existencia de Dios es una creencia propiamente básica (como que yo existo, que el mundo no fue creado hace cinco minutos, que tenemos dos manos, etc.), por lo que

La segunda edición con modificaciones importantes es de 1986. 
los creyentes no tienen la carga de la prueba y, aun más, Ralph McInerny que sostuvo que dado el orden y el carácter legaliforme de la naturaleza, la idea de Dios es casi innata, lo cual parece un argumento prima facie contra el ateísmo, por lo que la carga de la prueba recae en el ateo: se le ha dado la vuelta por completo al argumento de Flew.

En ocasiones se habla de la evolución doctrinal de los filósofos, de cómo fueron cambiando sus opiniones sobre diversos temas y cuáles fueron las causas de esos cambios. Es clásico, por ejemplo, hablar del primer y del segundo Wittgenstein, del Kant precrítico y del Kant de las grandes críticas, de las sucesivas reediciones de la filosofía de la ciencia que publicó Fichte, o del constante cambio que experimentó la filosofía de Schelling a lo largo de los muchos años que vivió. También se habla así, por ejemplo, en Platón, de los diálogos de juventud, de madurez, de vejez. Y Werner Jaeger puso en circulación la idea de la historia redaccional de la metafísica aristotélica. Vivir ciertamente es cambiar. Pensar, muchas veces también, es rectificar. Y en la práctica solo es verdadera la recta razón, es decir la razón rectificada, corregida. Ser un hombre de una sola idea puede ser algo terrible, pero ser hombre de todas las ideas o sin criterios es casi todavía peor. Sin razones ni justificación, sin argumentos que manifiesten los fundamentos adecuados para rectificar, los cambios no tendrían sentido.

Muchas veces, en España, he escuchado el cuento de que la filosofía analítica, al ver que el lenguaje da para lo que da, en realidad para poco, ha tenido que abrirse a temas más importantes y se ha encontrado con la filosofía. Si ha sido así, ha sido un encuentro maravilloso. En realidad ha sido siempre auténtica filosofía. Pensamiento riguroso y profundo que se corrige a sí mismo y busca la verdad mediante las argumentaciones más claras y fuertes que puede formular. Flew comenzó siendo ateo en su adolescencia, pero también fue comunista y lo dejó, primero como protesta contra la propaganda política mentirosa del partido comunista inglés después de la II Guerra Mundial, y posteriormente contra la invasión de Praga. Flew era también determinista y compatibilista y negaba la causalidad siguiendo los argumentos de Hume, pero después descubrió que los argumentos no probaban lo que pretendían, que todo y todos funcionaban como si las causas 
fueran reales, como si hubiera libertad y como si las leyes físicas dejaran espacio a la posibilidad de la libre elección de los hombres. Como puede verse, no se trata de cambios cosméticos, sino de auténticas conversiones filosóficas. Y cuando uno está dispuesto a reconocer la verdad donde se le manifiesta, se dispone por esa misma razón a reconocer también la verdad de Dios cuando pueda considerar las cosas con suficiente atención.

Pero la verdad sólo puede reconocerse cuando se puede exponer. La exposición de la verdad tiene lugar mediante el dialogo, aunque dadas las limitaciones humanas, muchas veces el diálogo debe llamarse propiamente disputa o discusión. Los medievales les llamaban Quaestiones Disputatae. Y han caracterizado la civilización cristiana. Los reyes españoles organizaron sonadas discusiones entre cristianos, musulmanes y judíos. Seguro que recordamos la discusión, de la que habló Benedicto XVI, transcurrida en Constantinopla en el S. XIV entre el Emperador y un sabio persa. Pero en Europa hoy simplemente han desaparecido: nadie tiene casi nunca ningún interés en debatir con nadie sobre nada. Pero en EEUU, a pesar de lo que pensemos de la sociedad americana, hay auténticas discusiones públicas. Ante públicos numerosos y retransmitidas en directo por televisión, también se pueden ver casi todas inmediatamente en YouTube 6 .

Y Flew ha discutido como ateo con muchos teístas en múltiples ocasiones a lo largo de décadas. Algunas de estas disputas son verdaderos acontecimientos públicos a los que asisten miles de personas y duran varios días. Como espectáculos tienen sus reglas y su parte de teatro, ya se entienda como drama o comedia, en el que los participantes cumplen los papeles asignados y los argumentos en muchas ocasiones rebotan en los contrarios sin causar mayores problemas ni inquietudes. Eso también forma parte del espectáculo. El propio Flew reconoce que eso le ocurrió con las discusiones con Plantinga o Swinburne. Pero a veces surgen sorpresas. Flew, por ejemplo, menciona el cuidadoso argumento cosmológico de Miethe para demostrar la existencia de Dios que no necesita del principio de razón sufi-

6 El 6 de noviembre del 2013, al buscar en YouTube “debate existence of God” se obtienen 634.000 resultados. Si juzgamos a partir de las tres primeras páginas son todos debates filosóficos públicos sobre la existencia de Dios entre ateos y creyentes. 
ciente, sino que se basa en el principio de causalidad existencial. Y subraya la discusión, con motivo del 50 aniversario del debate radiofónico en la BBC entre Russell y Copleston, que le enfrentó con William Lane Craig en el que éste se refirió a la existencia de Dios como la mejor explicación del origen del universo y del complejo orden que manifiesta. Pero, como Russell que musitaba: "No hay suficiente evidencia", Flew sostenía que "nuestro conocimiento debe detenerse en el Big-Bang".

Por el contrario, en el debate del 2004 se encontró enfrente de Gerald Schroeder y de John Haldane y, antes de empezar y para sorpresa de todos, anunció que ahora aceptaba la existencia de Dios. De ese modo, "el debate se transformó en una exploración conjunta de los desarrollos de la ciencia moderna que parecían apuntar a una Inteligencia más alta” (Flew 2012, 78). De este modo, corresponde ahora desarrollar la tercera parte de esta conferencia: los principales argumentos que se discuten para alcanzar la existencia de Dios.

¿Cuáles son los argumentos que convencieron a Flew de la existencia de Dios? Los argumentos filosóficos, si se miran detenidamente, son parecidos a los que habían sido expuestos por Tomás de Aquino siete siglos antes: realmente no hay novedades filosóficas de relevancia. Pero sí hay novedades, muchas y de gran calado, en los puntos de partida, es decir, en la exposición de los hechos científicos en los que se basan los principios metafísicos que se emplean en las demostraciones. No es lo mismo decir "Vemos, en efecto, que las cosas que carecen de conocimiento, como los cuerpos naturales, obran por un fin, como se pone de manifiesto porque siempre o muy frecuentemente obran de la misma manera para conseguir lo mejor; de ahí que llegan al fin no por azar, sino intencionadamente” que afirmar: "Lo que creo que ha conseguido hacer el ADN es mostrar, por medio de la casi increíble complejidad de las estructuras que son necesarias para producir (vida), que alguna inteligencia ha debido participar en el ensamblamiento de esos elementos extraordinariamente diversos. [Lo que asombra] Es la enorme complejidad del número de elementos y la enorme sutileza de las formas en que cooperan. La probabilidad de que todos esos elementos hayan podido encontrarse por casualidad en el momento ade- 
cuado es simplemente minúscula. La enorme complejidad [de los caminos] por los que fueron conseguidos los resultados es lo que me parece producto de la inteligencia” (Flew 2012, 79).

Desde los tiempos de Santo Tomás ha cambiado radicalmente nuestro conocimiento del mundo y eso implica que al menos nuestro modo de acceder a las explicaciones filosóficas ha de variar de manera consecuente. Por eso, permítaseme resumir en tres puntos la perspectiva de una argumentación contemporánea de la existencia de Dios, tomando como base la propia explicación de Flew.

El primer punto que se debe tratar es metodológico, pero eso no le impide ser realmente sustantivo porque expresa la disposición humana hacia la verdad. "Hacer una argumentación racional implica necesariamente proporcionar razones que sustenten una tesis. Supongamos entonces que no tenemos claro qué está arguyendo alguien que emite cierta afirmación, o imaginemos, más radicalmente, que ni siquiera estamos seguros de que esté arguyendo algo en absoluto: una forma de intentar comprender su afirmación consistiría en intentar descubrir qué pruebas, en caso de que haya alguna, aduce a favor de la verdad de sus tesis. Pues, si la afirmación es verdaderamente racional, si es realmente un argumento, debe ciertamente proporcionar razones científicas o filosóficas que la sustenten. Y todo lo que podría anular la afirmación, que induciría al hablante a abandonarla y admitir que era errónea, debe también ser expuesto. Pero si no hay ninguna razón ni ninguna prueba que pueda aducirse en su favor, entonces no hay ninguna razón por la que debamos considerarla un argumento" (Flew 2012, 86).

La argumentación ha de fundarse en razones científicas o filosóficas. Razones sólidas, capaces de resistir la inspección más detenida y seguir en pie. Razones claras que muestren todos los entresijos y estructuras de la realidad que expresan y afronten todas las distinciones que es preciso tener en cuenta. Razones consistentes con lo que ya sabemos, y con los modos ordinarios de juzgar y actuar que los hombres tomamos como buenos. $\mathrm{Y}$ el que ofrece razones las ofrece como verdaderas para aquel que quiera considerarlas: no puede obligarse a pensar, no existe ninguna verdad que 
pueda imponerse sino por su propia evidencia como verdad a aquel que piensa. Argumentar es hacer pensar más que convencer. Por eso lo primero de lo que debe prescindir el que argumenta es de querer vencer, como si la verdad fuera suya o tuviera partidarios. La verdad reúne a los hombres, no los divide. Se debe argumentar sin jactancia y sin triunfalismo: desde la humildad del que ha sido captado por la verdad.

En segundo lugar, la argumentación debe anclarse decididamente en el mejor conocimiento científico disponible. No se admiten adulteraciones: hay que conocer la ciencia dura, la investigación de vanguardia, es preciso estar al tanto de las hipótesis que se barajan para los proyectos científicos de futuro. No sirven las conclusiones de los artículos de divulgación ni las ruedas de prensa de los encargados de captar fondos para proyectos de investigación, ni las entrevistas en los mass media de los especialistas. Sin un estudio serio y profundo de las entrañas mismas de la investigación científica de al menos un campo científico importante no se puede hacer ninguna filosofía suficientemente profunda. Pero no basta nunca el conocimiento científico. Es preciso pasar decididamente a las cuestiones filosóficas, porque sólo a ese nivel la razón humana alcanza a plantear un conocimiento de la realidad suficiente para alcanzar los rastros de Dios en el universo y aprende a seguirlos con determinación ${ }^{7}$.

En este punto, el trabajo paciente de los cristianos que son científicos y filósofos no tiene sustituto posible. Es necesario presentar los argumentos de modos cada vez más vigorosos, lógicamente más claros, argumentativamente más significativos. No basta saber que hay en general buenos argumentos científicos que sirven de base para demostrar la existencia de Dios. Hay que descubrir el mejor modo de referirse a los hechos científicos que sirven de base a tales argumentos. Es conveniente simplificar la argumentación hasta hacerla asequible al que carece de sutilezas lógicas. Flew apunta con admiración la impresión que le causó el argumento contra el azar que se basaba en las probabilidades de que un soneto de amor de Shakespeare fuera tecleado por un grupo de monos: subrayaba el acierto

7 Me he ocupado de estos temas en (Moros 2003). 
de referir a una realidad breve y perfectamente asequible: un soneto, en vez de las obras completas. Destacó la parte inferencial y experimental del argumento: de hecho ni siquiera en una semana habían conseguido escribir ni el más breve monosílabo inglés, es decir, espacio, una letra y seguida de otro espacio. La inteligencia no tiene sustituto posible cuando se habla de intenciones y finalidades como las que se observan constantemente en los seres vivos.

Es de destacar que la discusión previa a la que tiene lugar la declaración teísta de Flew tuvo lugar casi un año antes con William Lane Craig y tuvo un fuerte contenido científico: la teoría cosmológica del Big Bang y la teoría del ajuste fino de las constantes cosmológicas para que sea posible la vida tuvieron mucho espacio y lograron concesiones notables por parte de Flew $^{8}$.

El propio Flew subraya los tres ámbitos científicos donde recae ahora mismo el peso del punto de partida de los argumentos a favor de la existencia de Dios: "La ciencia atisba tres dimensiones de la naturaleza que apuntan hacia Dios. La primera es el hecho de que la naturaleza obedece leyes. La segunda es la dimensión de la vida, la existencia de seres organizados inteligentemente y guiados por propósitos, que surgieron de la materia. La tercera es la propia existencia de la naturaleza. Pero no es solo la ciencia la que me ha guiado. También me ha ayudado la reconsideración de los argumentos filosóficos clásicos”(Flew 2012, 87).

Y así llegamos al tercer punto que me parece oportuno resaltar: la ciencia no concluye con la ciencia sino en la filosofía. "La ciencia en cuanto tal no puede proporcionar un argumento que demuestre la existencia de Dios" (Flew 2012, 131). Sería, por parte de cualquier persona razonablemente instruida, despreciar el legado filosófico de casi tres milenios de reflexión metafísica. Ser un hombre razonable significa descubrir que cuando eligió la ciencia como pasión y trabajo lo hacía como hombre y no como científico. Y que ahora que es científico, la verdad le debe seguir apasionándole como hombre: en la ciencia y en la vida. Le interesa la verdad de sus experi-

8 En castellano disponemos de una magnífica recopilación de artículos sobre la existencia de Dios muy atentos a los desarrollos contemporáneos de la ciencia en (Soler Gil 2005). 
mentos, le debe apasionar la verdad de sus teorías y debe, casi más todavía, motivarle la verdad de su vida personal, familiar y social. Juan Pablo II en su libro-entrevista Cruzando el umbral de la esperanza dijo que Dios es una cuestión del corazón, y que Santo Tomás había inaugurado toda una civilización situando al comienzo de la Suma Teológica las famosas cinco vías para demostrar la existencia de Dios (Juan Pablo II, 1994).

Por eso nadie puede conformarse con puros datos científicos. Es preciso sacar consecuencias filosóficas que puedan orientar nuestra vida a la verdad y guiarnos a la hora de hacer el bien. "Cuando extraemos consecuencia filosóficas de datos científicos, estamos pensando como filósofos... Mi preocupación se refería... a la cuestión fundamental de qué significa estar vivo y cómo se relaciona esto con el conjunto de nuestros conocimientos químicos y genéticos considerados como un todo. Pensar a este nivel es pensar como un filósofo... Tres áreas de investigación científica han resultado especialmente importantes para mí... La primera es la cuestión que me ha intrigado siempre y continúa intrigando a los científicos reflexivos: ¿Cómo llegaron a existir las leyes de la naturaleza? La segunda es una cuestión evidente para todos: ¿Cómo puedo emerger el fenómeno de la vida a partir de lo no vivo? Y la tercera es el problema que los filósofos legaron a los cosmólogos: ¿Cómo llegó a existir el universo (entendido por 'universo' todo lo que es físico)?”(Flew 2012, 87-89).

La verdad de estas cuestiones es el fruto de un entendimiento despierto que no se detiene sino hacia donde le lleva el razonamiento. No es una cuestión de fe y menos de fe fiducial o una cuestión de apuesta pascaliana, sino pura honradez intelectual. "Mi descubrimiento... ha sido un ejercicio de lo que tradicionalmente es conocido como teología natural... mi descubrimiento de lo divino ha sido una peregrinación de la razón” (Flew 2012, 90). En estos tiempos oscuros, en los que incluso a veces hay que pedir excusas para hablar de Dios, porque resulta que en algunos ambientes no es de buena educación, Flew sigue hablando de la ciencia buscada que ya Aristóteles llamó teología. Y habla de un camino de la razón, de una lógica, de una peregrinación o de un método: la búsqueda rigurosa de la verdad. Y no sólo en general, sino de modo bien determinado. No como Dawkins, 
que solo habla bien cuando describe de modo excelente el radar de los murciélagos, pero no parece que busque la verdad ni sepa buscarla con el arte dialéctico o filosófico necesario (Dawkins 1988)9.

En este punto Flew habla del argumento del diseño, que es algo completamente diferente del 'diseño inteligente' que a la postre resulta tan poco inteligente. En definitiva es la formulación contemporánea de la quinta vía tomista: “Quizás el argumento más popular e intuitivamente plausible a favor de la existencia de Dios sea el llamado argumento del diseño... Conduce a la idea de diseño desde la idea de orden... Los avances de dos áreas del conocimiento, de manera especial, me han llevado a esta conclusión. La primera el cuestión del origen de la leyes de la naturaleza, y las intuiciones al respecto de eminentes científicos modernos. La segunda es la cuestión del origen de la vida y de la reproducción” (Flew 2012, 91).

Para ilustrar su argumentación, Flew acude a diversas citas de científicos de renombre del s. XX, que muestran y manifiesta los primeros pasos del argumento. Por ejemplo Hawking: "Incluso si solo hay una teoría unificada posible, se trataría simplemente de un conjunto de leyes y ecuaciones. ¿Qué es lo que insufla fuego en las ecuaciones y hace que hay un universo que puedan describir?” (Stephen Hawking, Historia del tiempo, 2011, 174). "Hay una abrumadora impresión de orden. Cuanto más descubrimos sobre el universo, más constatamos que está gobernado por leyes racionales”. "Todavía tenemos la pregunta: ¿Por qué el universo se molesta en existir? Si se quiere, se puede definir a Dios como la respuesta a esa pregunta” (Hawking 2002 entrevista en Reason).

O Einstein: "Cualquiera que haya vivido la excitante experiencia de los descubrimientos en este ámbito [la ciencia] se siente conmovido por una profunda reverencia hacia la racionalidad que se manifiesta en la existencia..., la grandeza de la razón encarnada en la existencia."(Albert Einstein,

9 El capítulo 2 comienza justamente con la afirmación: “La selección natural es un relojero ciego" (Dawkins 1988, 15), se dedica a examinar minuciosa y brillantemente el maravilloso funcionamiento del radar de los murciélagos, después de aburrirse soberanamente, según confiesa él mismo, en el capítulo anterior con cuestiones filosóficas. Ojalá se hubiera aburrido, en realidad ni las conoce, ni se ha tomado el más mínimo interés por ellas (Giberson and Artigas 2012, 37-82; Plantinga 2007). 
Lettres a Maurice Solovine, Gauthier-Vilars, Paris 1956, 102-3). "Es evidente que subyace a toda labor científica de orden superior una creencia, parecida al sentimiento religioso, en la racionalidad o inteligibilidad del mundo... Esta firme creencia, -imbricada con un profundo sentimiento- en una mente superior que se revela en el mundo de la experiencia representa mi concepción de Dios" (Albert Einstein, Ideas and Opinions, Dell, Nueva York 1973, 49).

O Planck y Davies: “La religión y la ciencia natural luchan juntas en una incesante, indesmayable batalla contra el escepticismo y el dogmatismo, contra la increencia y la superstición... [Por tanto] iAdelante hacia Dios!” (Max Planck, en Charle Gillespie, Dictionary of Scientific Biography, Cribner, NY, 1975, 15) “La cuestión palpitante, dice Davies, es triple: ¿De dónde proceden las leyes de la naturaleza? ¿Por qué tenemos precisamente estas leyes y no otras? ¿Por qué tenemos precisamente un conjunto de leyes que conduce a gases informe hasta la vida, la conciencia, la inteligencia? Esta leyes 'parecen casi ideadas -finamente ajustadas, como han sostenido algunos comentaristas- para que la vida y la conciencia pudieran emerger'. Concluye que 'este carácter ajustado de la existencia física me parece demasiado fantástico para asumirlo simplemente como dado. Apunta a un significado subyacente más profundo de la existencia’. O palabras tales como propósito y diseño, dice, capturan solo imperfectamente de qué trata el universo. 'Pero no tengo absolutamente ninguna duda de que trata sobre algo’” (Flew 2012, 99) (Paul Davies, Discurso en la recepción del premio Templeton). "La ciencia se basa en la presunción de que el universo es totalmente racional y lógico en todos sus niveles. Los ateos afirman que las leyes [de la naturaleza] existen porque sí y que el universo es en último extremo absurdo. Como científico, me resulta difícil aceptar esto. Debe haber un fundamento racional inmutable en el cual encuentra su raíz la naturaleza lógica y ordenada del universo" (Davies, God for the 21st Century, Filadelfia, 2000, 12).

Se supone que es tarea propia de los profesores universitarios alentar ese maravillarse del espíritu que ha sido siempre el alma de todos los desarrollos importantes de la ciencia. Hay que recordar que en plena carrera 
para descubrir y aislar algunas partículas elementales aquel premio Nobel cerraba el laboratorio a las siete para que sus doctorandos pudieran ir a los conciertos con sus novias para poder ser creativos la mañana siguiente.

No existe ninguna explicación materialista satisfactoria para el fenómeno de un ser vivo con capacidad de reproducirse genéticamente (Flew $2012,109)$. "La cuestión filosófica que no ha sido resuelta por los estudios sobre el origen de la vida es la siguiente: ¿cómo puede un universo hecho de materia no pensante producir seres dotados de fines intrínsecos, capacidad de autorreplicación y una 'química codificada'? Aquí no estamos tratando de biología, sino que nos enfrentamos a una categoría de problemas enteramente diferente" (Flew 2012, 110). Y frente a esto el naturalismo solo puede presentar un gesto forzado de indiferencia, como el del que no puede saber en realidad nada. Pero, efectivamente, el primer gran sacrificado de todo materialismo es el conocimiento y el gran resultado de todo conocimiento siempre es Dios.

El conocimiento y el lenguaje no tienen ninguna explicación material. Flew se pregunta retóricamente: “¿Puede ser explicado el origen de un sistema de codificación química sin recurrir para nada al tipo de hechos que invocamos al explicar los códigos y lenguajes, los sistemas de comunicación, la impronta de las palabras ordinarias en el mundo material?” (Flew 2012, 112). Y de esa manera, puede seguir ampliando el horizonte del pensamiento al hilo del desarrollo de la ciencia contemporánea: “¿Cómo es que, aunque haya tantas otras opciones aparentes, estamos en un universo que posee exactamente ese peculiar conjunto de cualidades que hacen posible la vida? Se me ha ocurrido últimamente -debo confesar que, al principio, con cierto espanto de mi sensibilidad científica- que ambas cuestiones deben ser tratadas de forma hasta cierto punto congruente. Es decir, mediante la suposición de que la inteligencia, en lugar de emerger como un subproducto tardío de la evolución de la vida, en realidad ha existido siempre como la matriz, la fuente, la condición de la realidad física: que la sustancia de que está hecha la realidad física es sustancia mental. Es la mente la que ha compuesto un universo físico capaz de desarrollar vida, capaz de producir evolutivamente criaturas que saben y crean: criaturas 
que hacen ciencia, arte y tecnología" (Georges Wald, "Life and Mind in the Universe”, en Henry Margenau y Roy Abraham Varghese (ed.) Cosmos, Bios, Theos, Open Court, Las Salle, Ill., 1992, 218).

Y junto a los desarrollos científicos, la reflexión filosófica no puede seguir los hilos trenzados por la ilustración escocesa y alemana. "La revelación de un universo en devenir, en lugar de una entidad estática, eternamente inerte, cambiaba los términos de la discusión. Pero la moraleja de la historia era que, en último extremo, los asuntos que estaban en juego eran más filosóficos que científicos. Y esto me llevó de nuevo al argumento cosmológico" (Flew 2012, 120). Es necesario desmontar las críticas humeanas que sostienen la posibilidad de la existencia de un conjunto infinito de seres finitos que se explica a sí misma: un millón de ordenadores infectados por un virus no explica la existencia de ese virus. "Es bastante probable que, si hay un Dios, otorgue sentido a un universo como el nuestro, complejo y finito. Es muy improbable que un universo exista sin causa alguna, pero es bastante más probable que Dios exista sin causa alguna. Por tanto, el argumento que se remonta desde la existencia del universo a la existencia de Dios es un buen argumento inductivo" (Richard Swinburne, The existente of God, 152).

Pero la búsqueda de Dios no acaba con la formulación de un argumento que demuestre su existencia. Eso es mucho pero, a la vez, demasiado poco. Para dar por bueno cualquier argumento que demuestre su existencia necesitamos a la vez y siempre profundizar en la coherencia del concepto de Dios y entender de algún modo su acción en el mundo. Si demostramos la existencia de Dios y no buscamos un lugar para Él, ¿cómo podremos decir que existe? En palabras de Flew: ¿cómo es posible que exista una persona sin cuerpo? Y, si es de ese modo, ¿cómo identificarla? El propio Flew encuentra la respuesta en Thomas Tracy: una persona es un ser capaz de acciones intencionales, pero ningún argumento antidualista, implica que todos los agentes deban ser corporales. Dios desarrolla actividades intencionales únicas, por ejemplo, crear. Precisamente porque hay cosas que sólo Él puede hacer, puede ser identificado como tal, aunque nuestra comprensión de sus características sea radicalmente limitada. 
El mismo Flew, anota otro argumento debido a Brian Leftow: Si nos tomamos en serio la teoría de la relatividad, según la cual el tiempo es una dimensión más junto a las tres espaciales de la realidad, y sostenemos, además, que Dios no está en ningún lugar, entonces debemos sostener que tampoco se encuentra en ningún tiempo determinado, sino que propiamente es eterno. Dios es un ser atemporal. El problema, en consecuencia, radicará en el concepto de causa que sostengamos: si pensamos con Hume que la causa siempre va antes que el efecto, tendremos problemas para pensar a Dios. Pero si, con Aristóteles y Tomás, sostenemos que la prioridad de la causa es ontológica y no sólo ni principalmente temporal, entonces un Dios eterno puede perfectamente ser causa intemporal de lo que ocurre en el tiempo.

La teología natural analítica está alcanzando unos niveles de desarrollo, profundidad y alcance verdaderamente notables. Todas las crisis de la metafísica que se han repetido, una y otra vez, no han hecho más que volver a poner a nuestro pensamiento frente a Dios. Considerando a Dios el pensamiento muestra su verdadera talla, da su auténtica medida, podríamos decir. Quisiera terminar con un verso de Holderlin, que al decir de Heidegger (Heidegger 1994) nos concierne especialmente a nosotros, pero que en cualquier caso acierta a revelar lo decisivo de la teología natural: «Quien pensó lo más profundo, éste ama lo más vivo». Es preciso pensar también hoy a Dios porque sólo frente a Él el ser humano encuentra esa voz desconocida que le dice quién es él, cuál es su verdadero nombre, dónde se encuentra su destino eterno ${ }^{10}$.

Por último quisiera resumir una parábola que desarrolla Flew en su libro, porque a veces la imaginación alcanza donde el intelecto por sí mismo no se atrevería a aventurarse. Imaginemos que un smartphone es llevado por las olas a una remota isla habitada por una tribu que nunca ha tenido contacto con la civilización. Los nativos juegan con los números del teclado, y escuchan voces cuando marcan ciertas secuencias. Suponen que es el aparato el que produce estos ruidos. Algunos de los nativos más listos, los

10 Una propuesta en este sentido aparece desarrollada en (Sellés 2013).

ScientiaetFides 3(2)/2015 
científicos de la tribu, ensamblan una réplica exacta y marcan los números de nuevo. Oyen de nuevo las voces. La conclusión les parece obvia: esta peculiar combinación de cristales, metales y productos químicos produce lo que parecen ser voces humanas, y esto significa que las voces son simplemente propiedades del aparato.

Pero el sabio de la tribu convoca a los científicos a una discusión. Ha reflexionado prolongadamente sobre el asunto, y ha llegado a la conclusión de que las voces que salen del instrumento deben proceder de gente como ellos mismos, gente que está viva y consciente, aunque hablen en otro idioma. En lugar de presumir que las voces son simplemente propiedades del auricular, deberían investigar la posibilidad de que, a través de alguna misteriosa red de comunicación, hubiesen entrado en contacto con otros seres humanos. Quizás esta investigación podría conducir a una mejor comprensión del mundo más allá de su isla. Pero los científicos se limitan a reírse del sabio y dicen: «Mira, cuando dañamos el instrumento, las voces dejan de salir. Así que, obviamente, no son más que sonidos producidos por una rara combinación de litio, códigos de circuitos impresos y diodos parpadeantes».

“En esta parábola -comenta Flew- vemos cuán fácil es dejar que las teorías preconcebidas conformen el modo en que percibimos los datos, en lugar de dejar a los datos conformar nuestras teorías." (Flew 2012, 85). Cuando el sabio de nuestra parábola les dice a los científicos que investiguen todas las dimensiones de la evidencia, estaba sugiriendo que la no exploración de lo que parece prima facie razonable y prometedor excluye ipso facto la posibilidad de una mayor comprensión del mundo situado más allá de la isla habitada por la tribu. "Pues bien, a las personas que no son ateas a menudo les parece que no hay ningún prueba concebible que pudiera empujar a los ateos dogmáticos de mentalidad científica a admitir que 'después de todo, Dios podría existir'. Así que propongo a mis excompañeros ateos esta cuestión simple y central: ¿Qué tendría que ocurrir o haber ocurrido, que pudiera suponer una razón para que al menos considerarais la existencia de una mente superior?” (Flew 2012, 86).

"Pero imaginemos un final diferente. Los científicos aceptan, como hipótesis de trabajo. Después de más estudios, confirman la conclusión de 
que el teléfono está conectado a una red que trasmite las voces de personas reales. Ahora ya aceptan que existen seres inteligentes 'ahí fuera'. Algunos de los científicos van aún más lejos. Trabajan por descifrar los sonidos que oyen. Reconocen patrones y ritmos que les permiten comprender lo que se dice. $Y$ entonces todo su mundo cobra un nuevo sentido. Saben que no están solos. Y, en cierto momento, entran en contacto con el otro lado. La analogía es fácilmente aplicable. El descubrimiento de fenómenos como las leyes de la naturaleza -la red telefónica de la parábola- ha conducido a científicos, filósofos y otros a la existencia de una Mente infinitamente inteligente. Algunos aseguran haber establecido contacto con esta Mente. Yo no lo he hecho, no todavía. Pero quién sabe lo que podría ocurrir en el futuro? Quizás algún día pueda oír una Voz que dice: ‘Me oyes ahora?’” (Flew 2012, 132-133). Ahora la filosofía puede volver a entender que la sabiduría consiste en mantener el oído atento al ser de las cosas. Una escucha inteligente que confía y aprende; aprende y es capaz de mostrar lo que escucha; muestra y recibe confianza en esa circularidad ascendente que conforma la comunidad de los que buscan incansables la verdad y sólo a ella pretender servir.

\section{Referencias}

Artigas, Mariano. 2004. Ciencia, razón y fe, Pamplona: Eunsa.

Castrodeza, Carlos. 2000. "La realidad de las dos culturas como base del mito del relativismo cultural (Un enfoque bioantropológico).” Endoxa 12: 525-560.

Dawkins, Richard. 1988. El relojero ciego. Barcelona: Labor.

Diéguez Lucena, Antonio. 2000. ¿Hubo siempre dos culturas?” Contrastes. Revista interdisciplinar de filosofía 5: 43-60.

Flew, Antony, and Alasdair MacIntyre. 1972. New Essays in Theological Philosophy. London: SCM. $8^{\text {a }}$ reimpresión.

Flew, Antony. 1976a. Dios y la filosofía. Buenos Aires: El Ateneo.

-. 1976b. The Presumption of Atheism, and the Other Philosophical Essays on God, Freedom and Inmortality. London: Elek for Pemberton.

-. 2012. Dios existe. Madrid: Trotta. 
Frankfurt, Harry G. 2006. On Bullshit: sobre la manipulación de la verdad. Barcelona: Paidós.

Giberson, Karl, and Mariano Artigas. 2012. Oráculos de la ciencia. Científicos famosos contra Dios y la religión. Madrid: Encuentro.

Heidegger, Martin. 1994. Conferencias y artículos. Barcelona: Ediciones del Serbal. Hobsbawm, Eric. 1995. The age of extremes: The short twentieth century, 1914-1991. London: Abacus.

Juan Pablo II. 1994. Cruzando el umbral de la esperanza. Barcelona: Plaza \& Janes.

Kirk, Geoffrey S., and John E. Raven. 2008. Los filósofos presocráticos. Historia crítica con selección de textos. Madrid: Gredos.

Mackie, John L. 1994. El milagro del teísmo. Argumentos en favor y en contra de la existencia de Dios. Madrid: Tecnos.

Moros, Enrique, “Presupuestos de la demostración de la existencia de Dios”. Scripta Theologica, 35 (2003), 421-445.

-. 2008. La vida humana como trascendencia. Metafísica y antropología en la "Fides et ratio". Pamplona: Eunsa.

Pacho, Julián. 2011. “El drama de las «dos culturas». Un caso de irresponsabilidad epistémica.” Ludus Vitalis 19: 317-320.

Plantinga, Alvin. 2007. “The Dawkins Confusion. Naturalism 'ad absurdum'.” Books \& Culture. http://www.booksandculture.com/articles/2007/marapr/1.21.html.

Ratzinger, Joseph. 1973. Dios como problema. Madrid: Cristiandad.

Russell, Bertrand, and Frederick Copleston. 1978. Debate sobre la existencia de Dios. Valencia: Revista Teorema.

Sellés, Juan Fernando. 2013. Antropología de la intimidad. Libertad, sentido único y amor personal. Madrid: Rialp.

Soler Gil, Francisco (ed.) 2005. Dios y las cosmologías modernas. Madrid: BAC.

Snow, Charles P. 1959. The Two Cultures. Londres: Sage.

Swinburne, Richard. 1977. The Coherence of Theism. Oxford: Clarendon Press.

Weber, Max. 2009. La ciencia como profesión. Madrid: Biblioteca nueva. 